\title{
Intraorbital Abducens Nerve Schwannoma
}

\section{Rui Miguel Ferreira Rato ${ }^{1}$, Miguel Correia ${ }^{1}$, João Paulo Cunha ${ }^{2}$, Pedro Sutil Roque ${ }^{1}$}

\author{
Key words \\ - Abducens schwannoma \\ - Abduction preservation \\ - Intraorbital
}

\section{Abbreviations and Acronyms}

MRI: Magnetic resonance imaging

\author{
From the Departments of ${ }^{\mathbf{1}}$ Neurosurgery and \\ ${ }^{2}$ Ophthalmology, Centro Hospitalar de Lisboa \\ Central EPE, Lisboa, Portugal \\ To whom correspondence should be addressed: \\ Rui Miguel Ferreira Rato, M.D. \\ [E-mail: ruimfrato@gmail.com] \\ Citation: World Neurosurg. (2012) 78, 3/4:375.e1-375.e4. \\ DOI: 10.1016/j.wneu.2011.12.012 \\ Journal homepage: www.WORLDNEUROSURGERY.org \\ Available online: www.sciencedirect.com \\ 1878-8750/\$ - see front matter (C) 2012 Elsevier Inc. \\ All rights reserved.
}

\section{INTRODUCTION}

Schwannomas are tumors arising from the Schwann cells of the neural sheath of motor and sensory nerves. They are seen in all cranial nerves except optic and olfactory. They are also called neurilemmomas, neurinomas, and perineural fibroblastomas (7). They arise focally from the sheath of the nerve fascicle and present as well-defined eccentrically placed masses. This allows their dissection from the underlying neural bundle (7). Three clinical settings can be distinguished: localized schwannomas, in association with neurofibromas (as a part of Von Recklinghausen syndrome), or as schwannomatosis. Schwannomas occur in any age group and there is no sex preference. They are seen predominantly in the VIII cranial nerve. When occurring in extracranial locations, they commonly involve the head and the neck (9), the tongue (4), the nasopharynx and the parapharyngeal space (Io), and the brachial plexus (I6). Literature mentions schwannomas in the gastrointestinal tract $(20,22)$, the psoas muscle (II, 2I), and occasionally the external genitalia (I4).

Abducens schwannomas are rare tumors, representing less than $\mathrm{I} \%$ of all intra-
BACKGROUND: Schwannomas of the abducens nerve are extremely rare tumors. The tumor may be located within the cavernous sinus or more often at the prepontine region. However, literature research has identified only one case of isolated schwannoma of the orbit, arising from the terminal branches of the abducens nerve to the lateral rectus muscle. This is only the second report of an abducens nerve schwannoma located entirely intraconal.

CASE DESCRIPTION: We report a case of an intraorbital abducens nerve schwannoma in a 42-year-old man with no signs of neurofibromatosis. The lesion resulted in progressive diplopia and focal abducens palsy. The clinical, radiologic, and pathologic features are presented.

RESULTS: We point the particular aspects and discuss the possible treatments and approaches to preserve nerve function.

CONCLUSIONS: Being a benign lesion, one of the goals has always been total removal. The knowledge of the correct anatomic features made us believe that the VI nerve function could be preserved. Our case is the first example of a total removal with eye abduction preserved. Because of that, we believe that it is reasonable to aim for these goals in future cases. cranial schwannomas and about $13 \%$ of oculomotor nerve schwannomas, as reported in the literature (Ig). Patients present with VI nerve paresis. Clinical features and neuroradiologic imagery are frequently insufficient to reach an accurate preoperative diagnosis.
Schwannomas can show a variety of degenerative changes, such as cyst formation, calcification, hemorrhage, and hyalinization (5). Tumors that have undergone cystic degeneration (presumably because they have outgrown their blood supply) are

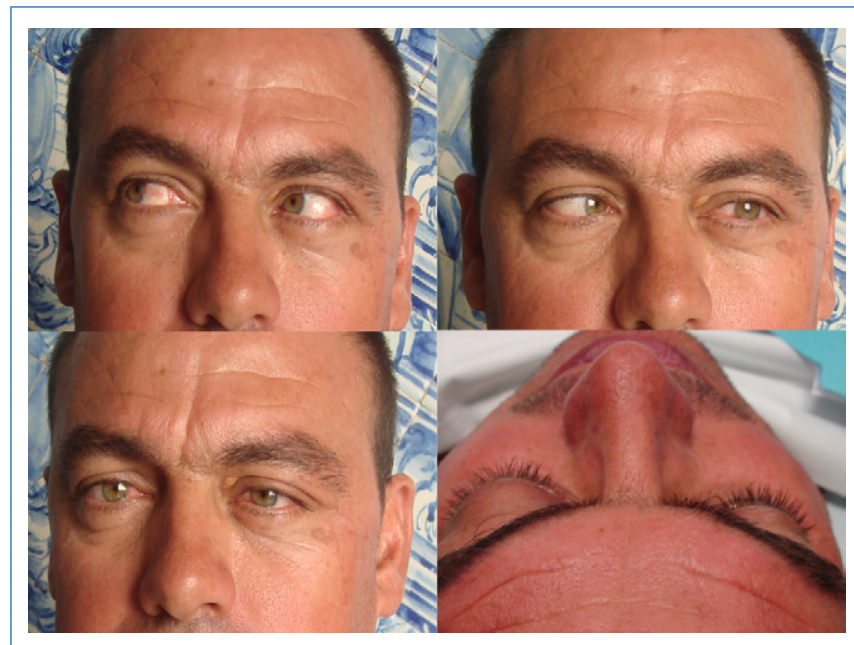

Figure 1. Preoperative image showing left VI nerve palsy and proptosis. 


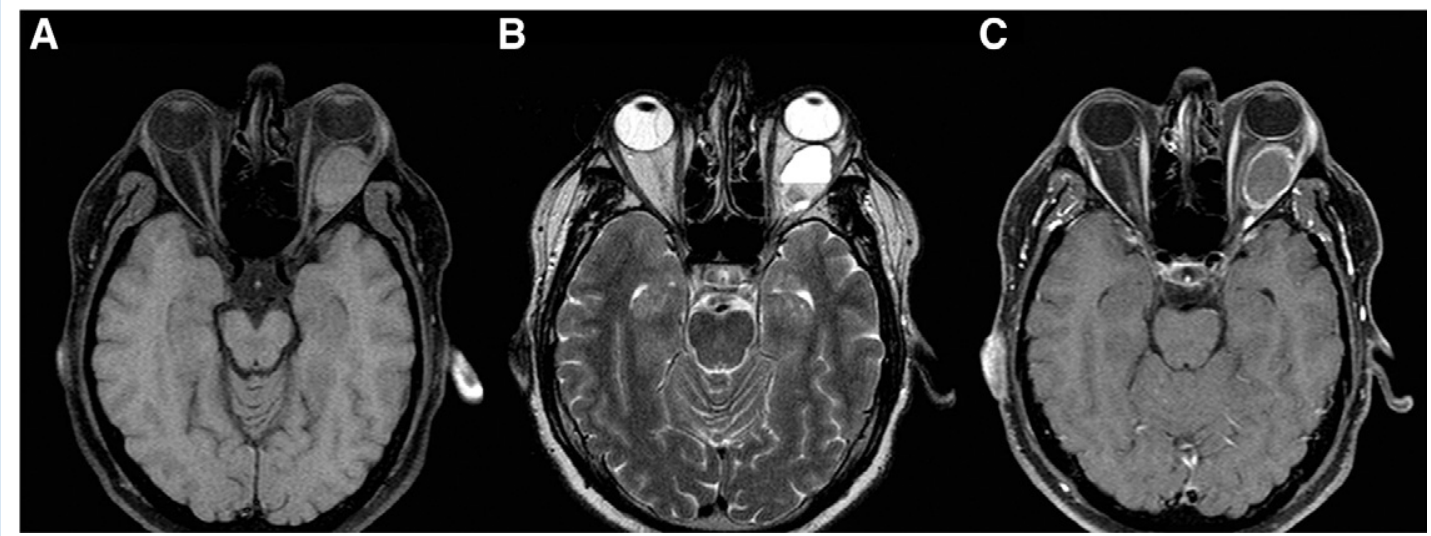

Figure 2. (A) Preoperative axial $T_{1}$-weighted magnetic resonance imaging (MRI) showing smooth contours and oval shape of the isointense lesion, and medial displacement of the intraconal portion of the optic nerve without enhancement or narrowing. (B) Preoperative axial $T_{2}$-weighted MRI showing a two-density cystic lesion with a fluid-fluid level. (C) Preoperative axial $T_{1}{ }^{-}$ weighted MRI showing the same lesion with homogeneous ring-shaped gadolinium enhancement.

sometimes capable of relatively rapid expansion because of enlargement of their cystic component (18).

Intraorbital schwannomas may arise from different nerves, but sometimes it may be difficult to identify their true origin (3). Housepian et al. (I2) were probably the first to hypothesize that these schwannomas most frequently originate from the nasociliary nerve. Other investigators (6) followed the same idea, although anatomic or clinical reports supporting such hypothesis are difficult to find in the main literature.

We report a case of a cystic schwannoma of the orbit, arising from the terminal branches of the abducens nerve to the lateral rectus muscle. Literature research has identified only one other abducens nerve schwannomas of the orbit, described by Irace et al. (13).

\section{CASE REPORT}

A 42-year-old man was admitted to our outpatient's clinic with a I-year history of progressive visual loss, diplopia, and painful proptosis on the left eye. No stigmata of neurofibromatosis type I or 2 was identified.

On ophthalmologic examination, the patient had a $70 \%$ decrease in left eye visual acuity, using the Snellen chart eye examination. On physical examination, a left eye proptosis was clearly identified and a left VI nerve palsy was the cause of the diplopia (Figure 1). No other neurological abnormalities were found.

Preoperative diagnosis of a benign intraorbital neoplasm was made by means of magnetic resonance imaging (MRI) scans (Figure 2).

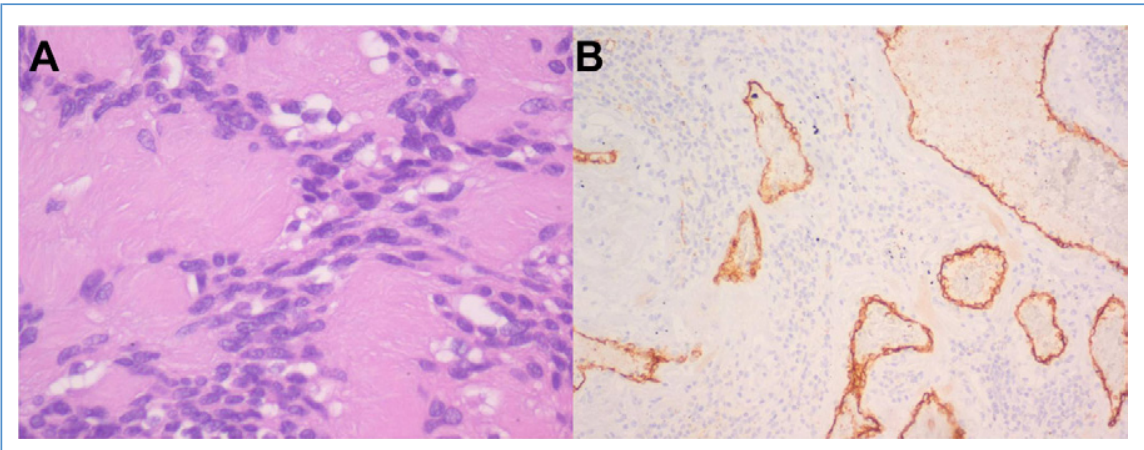

Figure 3. (A) Photomicrograph showing a typical histology of a schwannoma. Alternating hypercellular (Antoni A) and hypocellular areas (Antoni B) are identified (hematoxylin and eosin, $\times 400$ ). (B) The tumor cells show a diffuse nuclear positivity for $\mathrm{S} 100$ protein $(\times 40)$.

At this point we decided for a left lateral orbitotomy to perform an intraconal approach to the tumor. The lesion originated from the VI nerve terminal branches and attained a large size by splitting and displacing both lateral rectus muscle and nerve fibers. The surrounding structures were meticulous identified and gently detached from the tumor, namely the optic nerve. A firm, capsulated lesion was en bloc excised. The integrity of the majority of VI nerve fibers was confirmed at the end of the procedure.

Histopathologic examination of the specimen confirmed a cystic schwannoma (Figure 3).

At the immediate postoperative period, one could still see the left proptosis and VI nerve palsy.

At 6 months follow-up after surgery, the patient had no complaints of diplopia or proptosis and there was no detectable VI nerve paresis (Figure 4). An MRI was performed (Figure 5) at this time.

\section{DISCUSSION}

Ancient schwannoma is a rare variant, which was first described by Ackerman and Taylor in I95I (I), and predominantly consists of Antoni B tissue. This is characterized by degenerative changes such as cyst formation, calcification, hemorrhage, fibrosis, and cytologic atypia. It is typically asymptomatic and difficult to diagnose in the absence of clinical symptoms. Symptoms are usually due to its pressure on nerve roots or adjacent organs. 


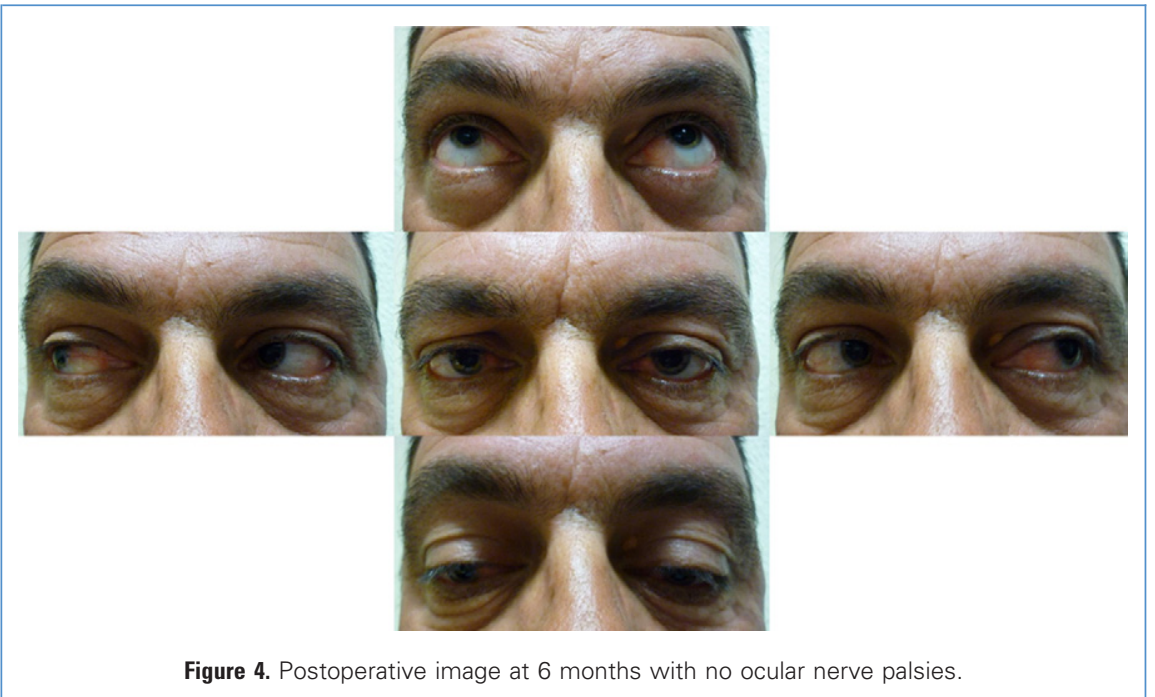

Cystic degenerations are rarely reported in schwannomas of the orbital region, olfactory groove, tentorial hiatus, posterior cavernous sinus, presacral region, maxillary region, and intraspinal and intraventricular locations. They are also observed in schwannomas arising from the vestibular or vagal nerve, jugular foramen, and thoracic neurilemmomas (I).

Tumor necrosis, thrombosis of the vessels with resultant necrosis plus hemorrhage or tumor neovascularity have been described as possible mechanisms of hemorrhage in the schwannoma. Blood in these cases often does not clot and forms a layer, depending on the viscosity and proteinaceous content of the cyst fluid. This often results in the formation of fluid-fluid levels. The Antoni B portion of the schwannoma can undergo degeneration to form cystic ar- eas that can progress to become large cysts (23). To our knowledge this is the first case being described as an intraorbital cystic schwannoma of the abducens nerve.

The lateral orbital approach was first proposed by Krönlein in I889 ( 17 ), and it was later modified by Berke (2). The lateral orbitotomy is useful for retrobulbar lesions, and it can be extended for more posterior lesions. The procedure involves temporary removal of the lateral wall of the orbit to gain access to the entire lacriinferolateral tumors. Examples of lesions suited to this approach include pleomorphic adenomas and some cavernous hemangiomas. In our patient, the lateral orbitotomy was the most suitable approach, and we were able to perform complete removal of the tumor. mal gland and lateral, superolateral, and
As described by Erdogmus et al. (8), when performing intraorbital surgery, anatomic knowledge of the innervation of the extraocular muscles allows one to minimize damage to neural structures. In particular, when approaching the superolateral compartment of the orbit through a lateral orbitotomy, the knowledge of the course and branching of the abducens nerve is required. This cranial nerve runs on the medial surface of the lateral rectus muscle, and these investigators report that the area nervosa of the nerve measures $3.55 \mathrm{~mm}$ on the right and $3.43 \mathrm{~mm}$ on the left. They identify this area in the middle third of the muscle. In our case, this knowledge was essential to preserve nerve integrity and function.

Based on the work of Erdogmus et al. (8), Irace et al. (13) proposed that the entry point of nerve fibers in the muscle (e.g., area nervosa or myoneural junction) (I5) is the zone where intraorbital schwannomas truly arise. Similar to the description by Irace et al. (13), in our case, we were able to demonstrate, preoperatively by MRI (Figure 2) and intraoperatively by identifying the area of attachment of the tumor, the origin of the schwannoma from the abducens nerve.

We summarize the main features by comparing our case with the one described by Irace et al. (13) (Table 1).

\section{CONCLUSIONS}

Although Housepian et al. (I2) hypothesized that these schwannomas most frequently originate from the nasociliary nerve, the case presented by Irace et al. (13)

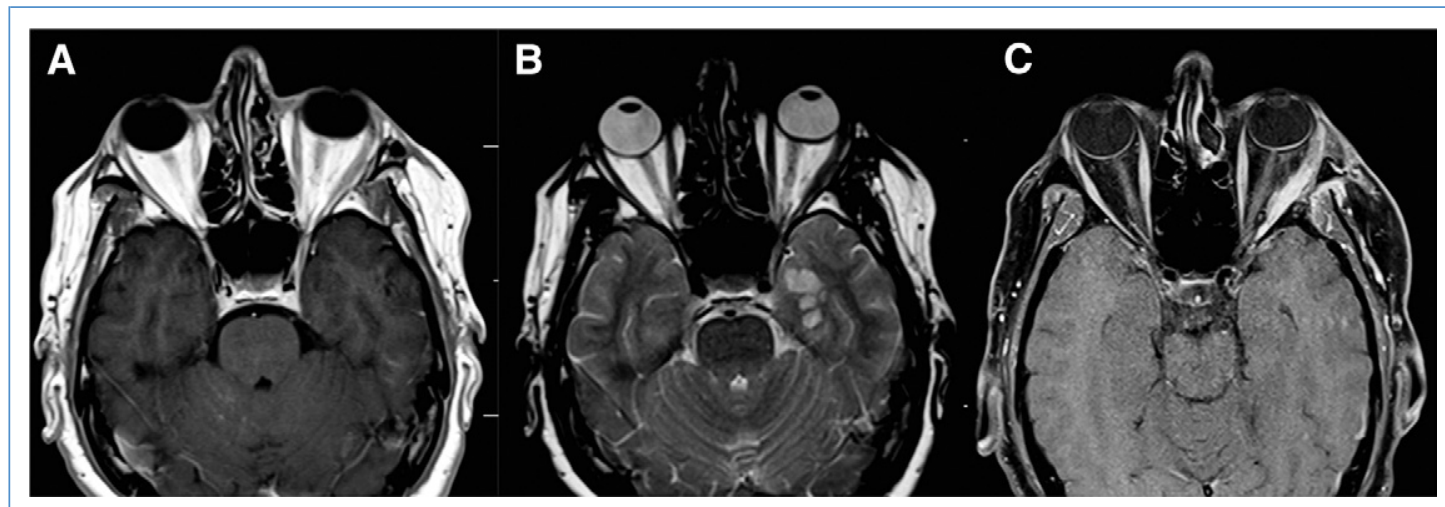

Figure 5. (A) Postoperative coronal $T_{1}$-weighted magnetic resonance imaging (MRI). (B) Postoperative axial $T_{2}$-weighted $M R I$. (C) Postoperative axial $\mathrm{T}_{1}$-weighted $\mathrm{MRI}$ with gadolinium, showing complete tumor removal. 


\section{Table 1. Patients with Intraorbital Abducens Nerve Schwannoma}

\begin{tabular}{|c|c|c|c|c|c|c|c|c|}
\hline Case & Author & Age/Sex & Clinical Presentation & $\begin{array}{c}\text { Tumor } \\
\text { Size }(\mathrm{cm})\end{array}$ & Tumor Type & $\begin{array}{l}\text { Surgical } \\
\text { Approach }\end{array}$ & $\begin{array}{l}\text { Extent of } \\
\text { Resection }\end{array}$ & $\begin{array}{l}\text { VI Nerve Function } \\
\text { (late follow-up) }\end{array}$ \\
\hline 1 & Irace et al., 2008 (13) & $55 / \mathrm{M}$ & Abducens nerve palsy; painless proptosis & $?$ & Solid schwannoma & Lateral orbitotomy & Total & Partial recovery \\
\hline 2 & Present case & $42 / \mathrm{M}$ & Abducens nerve palsy; painful proptosis & 2.2 & Cystic schwannoma & a Lateral orbitotomy & Total & Total recovery \\
\hline
\end{tabular}

shed a light over the true origin of this tumor. Our case confirmed that the true origin of this tumor is actually the VI nerve, most precisely at the point where it meets the lateral rectus muscle. The knowledge of these anatomic features was the key for a total removal with preservation of the VI nerve function (first case in literature).

In line with these results, we are now able to affirm that the total removal of this tumor is possible, as well as nerve function preservation.

\section{ACKNOWLEDGMENTS}

We thank Eva Falcão and Pedro Pauloro for assistance in preparing the manuscript.

\section{REFERENCES}

I. Ackerman LV, Taylor FH: Neurogenous tumors within the thorax; a clinicopathological evaluation of forty eight cases. Cancer 4:669-69I, I95I.

2. Berke RN: Modified Krönlein operation. AMA Arch Ophthalmol 51:609-632, I954.

3. Cantore G, Ciappetta P, Raco A, Lunardi P: Orbital schwannomas: report of nine cases and review of the literature. Neurosurgery 19:583-588, 1990.

4. Catalfamo L, Lombardo G, Nava C, Familiari E, Petrocelli M, Iudicello V, Ieni A, Barresi V, De Ponte FS: Tongue schwannoma: clinicopathological findings. J Craniofac Surg 223:1158-II6I, 2011.

5. Dahl I: Ancient neurilemmoma schwannoma. Acta Pathol Microbiol Scand A 85:812-818, 1977.
6. Delashaw JB Jr: 1993. Orbital anatomy and lateral orbitotomy. In: Rengachary SS, Wilkins RH, eds. Neurosurgical Operative Atlas, Vol. 4. Baltimore, MD: Williams \& Wilkins; 1993:75-83.

7. Enzinger FM, Weiss SW: I995. Benign tumors of peripheral nerves. In: Enzinger FM, Weiss SW, eds. Soft Tissue Tumors, 3 rd ed. St. Louis, MO: MosbyYear Book; I995:82I-888.

8. Erdogmus S, Govsa F, Celik S: Innervation of the extraocular muscles. J Craniofac Surg I8:I439-I446, 2007.

9. Gooder P, Farrington T: Extracranial neurilemmomata of the head and neck. J Laryngol Otol 942:243249, 1980.

Io. Hamza A, Fagan JJ, Weissman JL, Myers EN: Neurilemmomas of the parapharyngeal space. Arch Otolaryngol Head Neck Surg 123:622-626, 1997.

II. Hida K, Iwasaki Y, Abe H, Itamoto K, Kaneda K: Schwannoma in psoas muscle removed by the retroperitoneal approach. Br J Neurosurg 72:213-215, I993.

I2. Housepian EM, Trokel SL, Jakobiec FA, Hilal SK: Tumors of the orbit. In: Youmans JR, ed. Neurological Surgery, Vol. 5, 3rd ed. Philadelphia: Saunders; I990:337I-34II.

I3. Irace C, Davì G, Corona C, Candino M, Usai S, Gambacorta $\mathrm{M}$ : Isolated intraorbital schwannoma arising from the abducens nerve. Acta Neurochir Wien I50:I209-I2IO, 2008.

I4. Jiang R, Chen JH, Chen M, Li QM: Male genital schwannoma, review of 5 cases. Asian J Androl 53: 25I-254, 2003.

I5. Kakizaki H, Zako M, Nakano T, Asamoto K, Iwaki M: Myoneural junctions of extraocular muscles: distances from the orbital rim and widths. Ophthalmologica 2202:87-93, 2006.

I6. Katz AD, Passy V, Kaplan N: Neurogenous neoplasms of the major nerves of face and neck. Arch Surg 1031:51-56, I97I.
I7. Krönlein RU: Zur Pathologie und operativen Behandlung der Dermoidcysten der Orbita [in German]. Beitr Klin Chir 4:I49-I63, I889.

I8. Kutz JW Jr, Roland PS, Isaacson B, Backous DD, Talavera F, Gianoli GJ, Slack CL, Meyers AD: Acoustic neuroma. Medscape reference. Available at: http://emedicine.medscape.com/article/882876overview\#aoro4. Accessed June 6, 2011.

I9. Nakamura M, Carvalho GA, Samii M: Abducens nerve schwannoma: a case report and review of the literature. Surg Neurol 573:183-188 [discussion: I88-I89], 2002

20. Prevot S, Bienvenu L, Vaillant JC, de Saint-Maur PP. Benign schwannoma of the digestive tract: a clinicopathologic and immunohistochemical study of five cases, including a case of esophageal tumor. Am J Surg Pathol 234:43I-436, 1999

2I. Rajagopal KV, Lakhkar BN: Solitary giant neurilemmoma in the psoas muscle. Indian J Radiol Imaging I24:55I-552, 2002.

22. Sakai F, Sone S, Yanagisawa S, Ishii Z: Schwannoma of the lesser omentum. Eur J Radiol 82:II3-II4, I988.

23. Santhosh K, Kesavadas C, Thomas B, Gupta AK, Kapilamoorthy TR, Radhakrishnan VV: Fluidfluid levels in cystic lumbosacral schwannomas: a report of three cases. Singapore Med J 50I:I6-2I, 2009.

Conflict of interest statement: The authors declare that the article content was composed in the absence of any commercial or financial relationships that could be construed as a potential conflict of interest.

Received 21 September 2011; accepted 02 December 2011; published online 11 December 2011

Citation: World Neurosurg. (2012) 78, 3/4:375.e1-375.e4.

DOl: 10.1016/j.wneu.2011.12.012

Journal homepage: www.WORLDNEUROSURGERY.org

Available online: www.sciencedirect.com

1878-8750/\$ - see front matter (C) 2012 Elsevier Inc. All rights reserved. 